\title{
Gender differences in clinical status at time of coronary revascularisation in Spain
}

\author{
M D Aguilar, P Lázaro, K Fitch, S Luengo
}

J Epidemiol Community Health 2002;56:555-559

\begin{abstract}
Objective: To study gender differences in clinical status at the time of coronary revascularisation.
Design: Retrospective study of clinical records. Two stage stratified cluster sampling was used to select a nationally representative sample of patients receiving a coronary revascularisation procedure in 1997.

Setting: All of Spain.

Main outcome measures: Odds ratios $(O R)$ in men and women for different clinical and diagnostic variables related with coronary disease. A logistic regression model was developed to estimate the association between coronary symptoms and gender.

Results: In the univariate analysis the prevalence of the following risk factors for coronary heart disease was higher in women than in men: obesity $(O R=1.8)$, hypertension $(O R=2.9)$ and diabetes $(O R=2.1)$. High surgical risk was also more prevalent among women $(O R=2.6)$. In the logistic regression analysis women's risk of being symptomatic at the time of revascularisation was more than double that of men (OR=2.4).

Conclusions: Women have more severe coronary symptoms at the time of coronary revascularisation than do men. These results suggest that women receive revascularisation at a more advanced stage of coronary disease. Further research is needed to clarify what social, cultural or biological factors may be implicated in the gender differences observed.
\end{abstract}

See end of article for authors' affiliations

Correspondence to: Dr M D Aguilar, Técnicas Avanzadas de Investigación en Servicios de Salud, SL (TAISS), Calle Cambrils, 41-2, 28034

Madrid, Spain;

daguilar@taiss.com

Accepted for publication 24 April 2001

M any studies have shown large variations in the use of health services by such sociodemographic variables as social class, income, educational level, race or gender. ${ }^{1-7}$ Gender has traditionally been used as a potential confounding factor in most studies of health inequalities, but recent studies suggest that it may be predictive of health services use. ${ }^{58}$ In general, women have poorer perceived health status than men, with higher morbidity and greater use of primary health care services. For the same level of morbidity, however, women tend to use fewer hospital services than do men. ${ }^{5}$

Cardiovascular disease, and particularly coronary heart disease, is one of the most prevalent health conditions in the developed world. Coronary disease has classically been considered a man's disease, in part because it appears later in women than in men. Despite the fact that mortality rates in men are considerably higher than those in women, however, women's longer life expectancy means that the number of deaths from coronary disease in the developed countries is about the same in both sexes.' Given the huge social and health implications of coronary disease, large amounts of resources have been allocated for its treatment in recent years, with particular attention to providing equipment and improving hospital infrastructure for the performance of the two most widely used procedures for coronary revascularisation: percutaneous transluminal coronary angioplasty (PTCA) and coronary artery bypass graft surgery (CABG).

Whether or not women truly have poorer access to diagnostic and therapeutic procedures for coronary disease is a subject of debate in the scientific literature. A number of studies have shown that women's coronary symptoms tend to be more severe or of longer duration than those of men at the time of coronary angiography, for example, and that this phenomenon may reflect a pattern of referral bias. ${ }^{10-12}$ The objective of this study was to investigate the possible existence of gender differences in patients who receive coronary revascularisation procedures by studying the association between sex and clini- cal status at the time of coronary revascularisation. The data for this analysis were obtained from a larger study designed to determine how appropriately coronary revascularisation procedures were used in Spain in 1997.

\section{METHODS}

We carried out a retrospective study of coronary revascularisation procedures performed in Spain during 1997. Procedures were excluded if another intervention had been performed at the same time as revascularisation (for example, valvuloplasty), or if the patient had received previous bypass surgery. Previous angioplasty was not grounds for exclusion. Two stage stratified cluster sampling was used to select a sample of 3645 coronary revascularisations (1934 PTCAs and 1711 CABGs) from the 27156 such procedures carried out in Spain in 1997 (18 091 PTCAs and 9065 CABGs). For each procedure, the sample was stratified by hospital type (public or private) and volume of procedures (high: $>400$ for PTCA and $>200$ for CABG; medium: 250-399 for PTCA and 100-199 for CABG; and low: $<250$ for PTCA and $<100$ for CABG). Within each stratum the sample size was self weighted. The first stage sampling units were the clusters (hospitals), with the probability of selection proportional to the size of the cluster, following the methodology proposed by Silva. ${ }^{13}$ All hospitals selected agreed to participate in the study. The second stage units were the clinical records of patients who had received a coronary revascularisation procedure; these were selected within each cluster by simple random sampling. Data from the clinical records were collected by trained physicians using pre-tested data collection forms that had been designed to permit classification of the level of appropriateness of each coronary revascularisation procedure in accordance with appropriateness criteria previously developed by an expert Spanish panel using the RAND/University of California at Los Angeles appropriateness method. ${ }^{14} 15$ 
For the purpose of this study, the data were grouped into four types of variables: (1) sociodemographic variables: age and sex; (2) clinical variables: obesity, hypertension, diabetes, chronic obstructive pulmonary disease, peripheral vascular disease, cerebrovascular disease, high surgical risk $(>18$ points on the Parsonnet scale), all considered as dichotomous variables (yes/no); symptoms, which were grouped into three categories: asymptomatic (persons with no chest pain or infarction in the three months before revascularisation), stable disease (persons with chronic stable angina or in the post-myocardial infarction period), and unstable disease (persons with unstable angina or acute myocardial infarction); (3) medical management prior to revascularisation (only for patients with stable disease and those with unstable angina), grouped into two categories: optimal/suboptimal; and (4) diagnostic test results: stress test in the previous year (yes/no); stress test results, if a conclusive result was available in the previous year (positive/negative); coronary angiography results (left main disease, three vessel disease, two vessel disease with involvement of the proximal left anterior descending (PLAD) artery, two vessel disease without PLAD, one vessel disease with PLAD, one vessel disease without PLAD, and non-significant vessel disease); left ventricular ejection fraction (LVEF): normal ( $>50 \%$ ) or reduced $(\leqslant 50 \%)$. Optimal medical management for chronic stable angina patients (without contraindications) was defined as receipt of at least two of the following three drug classes: nitrates, $\beta$ blockers or calcium channel blockers. Optimal treatment for unstable angina patients (without contraindications) was considered to be receipt of: (a) oral nitrates or intravenous nitroglycerine, and (b) aspirin or intravenous heparin, and (c) $\beta$ blockers or calcium channel blockers.

The crude association between sex and the different clinical and diagnostic variables was measured by univariate analysis. PTCA and CABG procedures were weighted (by a factor of 1.253 and 0.7116 , respectively) to make the sample representative of all revascularised patients. The measure of association used was the odds ratio (OR), with 95\% confidence intervals (CI).

In the multivariate analysis, a logistic regression model was developed to estimate the association between coronary symptoms and sex after adjusting for possible confounding variables. In this model, the existence of coronary symptoms was the dependent variable, and sex was an independent variable. Coronary symptoms were considered to have two possi- ble values: 1 (symptomatic, grouping patients with stable and unstable disease) and 0 (no symptoms in the three months before revascularisation). In addition to sex, the maximum model included the following possible confounders as independent variables: age, obesity, diabetes, hypertension, surgical risk, type of vessel lesion, and left ventricular ejection fraction. The simplest (most parsimonious) model was chosen. A variable was considered to be a confounder in the association between symptoms and sex when it changed the OR of the variable sex by more than 0.02 units. Variables with no confounding effect were eliminated from the model. The log likelihood ratio was used to test for goodness of fit. The level of significance for all comparisons in the study was $\alpha=0.05$.

\section{RESULTS}

Women made up 18.4\% of all revascularised patients; this proportion was the same for both PTCA and CABG. The mean age of revascularised women in the sample was 68 years, as compared to 62 years for men $(\mathrm{p}<0.05)$.

In the univariate analysis, women more frequently suffered three of the six comorbidities measured: obesity $(\mathrm{OR}=1.8$, 95\% CI: $1.5,2.2)$, hypertension (OR=2.9, 95\% CI: $2.4,3.5)$, and diabetes $(\mathrm{OR}=2.1,95 \% \mathrm{CI}: 1.8,2.6)$ (table 1$)$. No statistically significant differences by sex were observed for chronic obstructive pulmonary disease, peripheral vascular disease or cerebrovascular disease (data not shown). Women had more serious coronary disease than men: the OR for symptoms (either stable or unstable) in women was 2.5 (95\% CI: 1.7, 3.5). For those patients who had symptoms, the OR of having unstable symptoms was 1.3 in women (95\% CI: 1.1, 1.6). Women also more often had high surgical risk than men, with an OR of 2.6 (95\% CI: 2.1, 3.3). No statistically significant linear associations were found between sex and left ventricular ejection fraction, with an OR for women of having a reduced ejection fraction of 0.9 (95\% CI: $0.7,1.1)$, or between sex and extent of vessel disease $\left(\chi^{2}\right.$ test for trend $0.02, \mathrm{p}=0.9$ ). Women were less likely than men to have suboptimal medical treatment, with an OR of 0.7 (95\% CI: 0.6, 0.9).

In the multivariate analysis (table 2), the association between the existence of coronary symptoms and female sex was maintained. The maximum model was made up of the following independent variables: sex, vessel disease, age, left ventricular ejection fraction, surgical risk, hypertension, obesity, and diabetes. The latter two variables were left out of the

Table 1 Univariate analysis of association between sex and different variables (weighted data)

\begin{tabular}{|c|c|c|c|}
\hline & Men n (\%) & Women n (\%) & OR $(95 \% \mathrm{Cl})$ \\
\hline \multicolumn{4}{|l|}{ Risk factors } \\
\hline Obesity & 501 (17) & $182(27)$ & $1.8(1.5 \text { to } 2.2)^{*}$ \\
\hline Hypertension & $1294(44)$ & 462 (69) & $2.9(2.4$ to 3.5$)$ * \\
\hline Diabetes & $605(21)$ & $227(37)$ & $2.1(1.8$ to 2.6$) *$ \\
\hline \multicolumn{4}{|l|}{ Coronary symptoms } \\
\hline Symptomatic coronary disease & $2627(88)$ & $635(95)$ & $2.5(1.7 \text { to } 3.5)^{*}$ \\
\hline Unstable coronary disease (for symptomatic patients only) & $1418(54)$ & $387(61)$ & $1.3(1.1$ to 1.6$) \dagger$ \\
\hline \multicolumn{4}{|l|}{ Clinical status at revascularisation } \\
\hline High surgical risk & $218(7)$ & 115 (17) & $2.6(2.1$ to 3.3$)$ * \\
\hline Reduced LVEF & $847(29)$ & $173(26)$ & $0.9(0.7$ to 1.1$)$ \\
\hline Stress test not done & $1497(51)$ & $431(65)$ & $1.8(1.5 \text { to } 2.1)^{*}$ \\
\hline Positive stress test (only patients with conclusive stress test result) & $1230(91)$ & $186(89)$ & $0.7(0.5$ to 1.2$)$ \\
\hline $\begin{array}{l}\text { Suboptimal medical treatment (only patients with chronic stable angina, } \\
\text { post-myocardial infarction or unstable angina) }\end{array}$ & $567(23)$ & $108(18)$ & $0.7(0.6$ to 0.9$) \dagger$ \\
\hline \multicolumn{4}{|l|}{ Vessel disease $\ddagger$} \\
\hline Left main & $233(8)$ & $36(5)$ & Reference \\
\hline Three vessels & $651(22)$ & $169(25)$ & $0.6(0.4$ to 0.9$)$ \\
\hline Two vessels with PLAD & $436(15)$ & $100(15)$ & $0.7(0.4$ to 1.0$)$ \\
\hline Two vessels without PLAD & $455(15)$ & $105(16)$ & $0.7(0.4$ to 1.0$)$ \\
\hline One vessel with PLAD & $369(12)$ & $91(14)$ & $0.6(0.4$ to 1.0$)$ \\
\hline One vessel without PLAD & 799 (27) & $165(25)$ & $0.8(0.5$ to 1.1$)$ \\
\hline No significant disease & $30(1)$ & $1(0.2)$ & $4.6(0.6$ to 94$)$ \\
\hline
\end{tabular}


Table 2 Logistic regression analysis of association between coronary symptoms (dependent variable) and sex (independent variable), adjusting for vessel disease, age, LVEF, surgical risk and hypertension

\begin{tabular}{|c|c|c|}
\hline Variable & OR & $95 \% \mathrm{Cl}$ \\
\hline \multicolumn{3}{|l|}{ Sex } \\
\hline Male & 1.0 & \\
\hline Female & 2.4 & $(1.7 \text { to } 3.6)^{*}$ \\
\hline \multicolumn{3}{|l|}{ Vessel disease } \\
\hline Left main & 1.0 & \\
\hline 3 vessels & 0.9 & $(0.6$ to 1.3$)$ \\
\hline 2 vessels with PLAD & 0.9 & $(0.6$ to 1.3$)$ \\
\hline 2 vessels without PLAD & 1.1 & $(0.7$ to 1.7$)$ \\
\hline 1 vessel with PLAD & 1.4 & $(0.8$ to 2.2$)$ \\
\hline 1 vessel without PLAD & 1.3 & (0.9 to 2.0$)$ \\
\hline Non-significant & 0.9 & $(0.3$ to 2.6$)$ \\
\hline \multicolumn{3}{|l|}{ Age } \\
\hline 1 year increment & 0.99 & (0.98 to 1.0$)$ \\
\hline \multicolumn{3}{|l|}{ LVEF } \\
\hline Reduced & 1.0 & \\
\hline Normal & 1.3 & $(1.0$ to 1.6$) \dagger$ \\
\hline \multicolumn{3}{|l|}{ Surgical risk } \\
\hline Low/moderate & 1.0 & \\
\hline High & 1.4 & (0.9 to 2.2 ) \\
\hline \multicolumn{3}{|l|}{ Hypertension } \\
\hline No & 1.0 & \\
\hline Yes & 1.3 & $(1.0$ to 1.6$) \dagger$ \\
\hline
\end{tabular}

final model as they did not exhibit the behaviour of confounding variables. After adjusting the logistic regression model for confounding variables, women's OR for coronary symptoms was 2.4 (95\% CI: 1.7, 3.6). The global model was statistically significant $(\mathrm{p}<0.0001)$.

\section{DISCUSSION}

The results of our study show that women have a poorer clinical status at the time of coronary revascularisation than men: they more frequently suffer comorbid conditions and more severe coronary symptoms. This finding seems to suggest a delay in women's receipt of these therapeutic procedures in comparison with men. The reason for delayed revascularisation in women may be attributable to gender differences occurring in any (or all) phases of the disease process: in the suspicion of coronary disease, in the performance of diagnostic tests, or in the treatment of disease once it is detected.

With regard to possible gender differences in the suspicion of coronary disease, there are a number of biological factors that lead physicians to suspect coronary disease less often in women than in men. In the first place, coronary disease tends to occur later in women-on average, women are 7 to 10 years older than men at its onset. ${ }^{96}$ Furthermore, the greater prevalence of diabetes in women means that they are more likely than men to present with coronary disease in the absence of anginal symptoms. ${ }^{17}$ Also, chest pain in women is less likely to be of coronary origin than it is in men, ${ }^{18}$ therefore physicians are apt to think of other types of disease in this situation. In our study women were, in fact, an average of six years older than the men, and had a greater prevalence of risk factors (obesity, hypertension, and diabetes). However the study design (only revascularised patients were included) does not permit generalisation to the entire population of patients with coronary disease. In addition to these biological factors, cultural reasons have been described that give rise to the widespread belief-among both physicians and society at large-that coronary disease is a disease more typical of men. ${ }^{19-21}$

Gender differences in the use of diagnostic tests, once coronary disease is suspected, have also been widely described in the literature. As our study included only patients who had already been revascularised, they had obviously all received a coronary angiogram. This was not the case, however, for stress testing. We found that women's "risk" of not having received a stress test in the year before revascularisation was double that of men (OR: 1.8; 95\%CI: 1.5, 2.1). Some studies have attributed these types of differences to physician bias when referring patients for diagnostic testing, especially for such sophisticated tests as coronary catheterisation. ${ }^{19-21}$ This bias is based on the general perception that men play a more important social part and contribute more to society than do women. It has also been reported that women themselves frequently delay undergoing aggressive diagnostic procedures such as coronary catheterisation and even less invasive procedures such as stress testing. ${ }^{22}$ In addition, many diagnostic tests for coronary disease are less sensitive and specific in women than in men. ${ }^{23}$ This is because research related with these tests has classically been carried out almost exclusively in men. In our sample, there was no statistically significant association between stress test results (positive or negative) and sex in the subgroup of patients with a conclusive stress test result. Finally, certain social factors such as the lower educational level and smaller purchasing power of older women in Spain could constitute an obstacle to their access to some health services. ${ }^{5}$ Any of the aforementioned circumstances-physician bias, women's refusal or postponement of diagnostic procedures, lower sensitivity and specificity of diagnostic procedures or difficulty of access to health services-would result in women being diagnosed with coronary disease at later stages than men.

Gender differences may also exist with regard to treatment of coronary disease. Many studies have found that, for the same level of clinical severity, women receive fewer effective treatments than men ( $\beta$ blockers, thrombolytic therapy in acute infarction, and even coronary revascularisation)..$^{161824-30}$ Although fewer in number, other studies have reported that sex was not a factor in predicting the intensity of medical treatment in patients with myocardial infarction, ${ }^{31}$ or that no gender bias in favour of men was found in referral for cardiac catheterisation $^{32}$ or for revascularisation. ${ }^{33}$ However, the finding in our study that women's clinical situation was more severe than men's could be a result of differences in treatment: women may need to be in a more advanced stage of disease to have access to revascularisation. With regard to medical treatment, we found that women had a slightly higher percentage of optimal medical treatment, which apparently contradicts the hypothesis that women receive less effective treatment. However, our study population — of revascularised patientscannot be considered representative of all patients with coronary disease, and it is possible that, just as women need to be more severely clinically ill to be referred for revascularisation, physicians also tend to exhaust the possibilities of medical treatment in women before resorting to revascularisation. No information was available from our study about treatment with thrombolytic therapy in acute infarction. The reasons for differences in the treatment of coronary patients could be similar to those suggested for diagnostic delay: physician bias because of cultural reasons or the lack of scientific evidence because, the same as with diagnostic tests, almost all research on the treatment of coronary disease has been carried out in men. ${ }^{34}$ Added to this possible physician bias is the fact that women with coronary pain tend to wait longer than men to visit the doctor; they often go to the hospital at such an advanced stage of infarction that thrombolytic treatment is ineffective. ${ }^{35}$ Another hypothesis suggested by some authors is that the differential use of coronary revascularisation in women may be less a problem of "underuse" in women than one of "overuse" in men. ${ }^{16}{ }^{27}$ However, we did not find any differences by gender in the proportion of inappropriate revascularisation procedures or "overuse" in our study, ${ }^{15}$ nor did a US study find significant differences between men and women in 


\section{Key points}

- Coronary heart disease is a major cause of mortality among women, although it has classically been considered a man's disease.

- Women have more severe coronary symptoms than men at the time of revascularisation, independently of age and other risk factors.

- These findings suggest gender differences in the treatment of coronary heart disease that may be attributable to delayed diagnosis, unequal access to treatments or poorer prognosis.

- Further research is needed to elucidate the causal relations among these factors and to ensure that women with coronary symptoms receive equitable care.

\section{the proportion of inappropriate revascularisation procedures. $^{36}$}

Another area of possible differences between the sexes relates to prognosis, although this is a controversial subject. Some studies have found that, for the same clinical severity of coronary disease, women have higher mortality than men. ${ }^{26}$ This fact is considered to be associated with poorer treatment of coronary disease in women ${ }^{25}$ and social factors such as lower socioeconomic level or less social support than men. ${ }^{37}$ Other authors conclude that women's excess mortality is attributable to more reduced ventricular function. ${ }^{38}$ This in turn may be attributable to the disease evolving for a longer time without receiving adequate medical or surgical treatment.

Some limitations in this study with regard to data collection should be noted. It is well known that clinical records do not always faithfully document all relevant information pertaining to the patient's medical history, medications or procedures performed. Thus, it is possible that missing information may have resulted in the misclassification of some patients with regard to one or more of the study variables. However, data for this study were collected by trained physicians who reviewed the entire clinical record and all accompanying documents, not merely an abstract form or discharge report. As the diagnostic tests performed on a patient being evaluated for coronary heart disease are generally documented in a separate report in the patient file, it is unlikely that much of this information was missed. Furthermore, even if we assume that some information was missing or overlooked in the review, there is no reason to suppose this would have occurred differentially for male and female patients.

In summary, our study shows that women have more coronary symptoms at the time of coronary revascularisation than do men. This could be attributable to differences in the treatment of coronary disease such as delayed disease diagnosis, unequal access to effective treatments, and poorer prognosis. Several factors have been proposed that may help explain these phenomena: physician bias because of cultural reasons or lack of scientific evidence, delay on the part of women in seeking medical advice, reluctance of women to undergo certain diagnostic or therapeutic procedures, social conditions unfavourable to women, and lack of sensitivity and specificity in some diagnostic tests in women. Further research is needed to explore the causal relations between the factors described and the gender disparities observed, and to identify mechanisms to ensure equitable care for women with coronary disease.

\section{Authors' affiliations}

M D Aguilar, P Lázaro, K Fitch, S Luengo, Técnicas Avanzadas de Investigación en Servicios de Salud, SL (TAISS), Madrid, Spain

Funding: this research was partially supported by a grant from the Fondo de Investigación Sanitaria of the Spanish Ministry of Health and Consumer Affairs (Exp. 95/1956).

Conflicts of interest: none.

\section{Policy implications}

- Health institutions such as specialist societies, insurance companies, and policy makers should carry out campaigns to heighten physician awareness of the frequency and importance of cardiovascular disease in women and of the need for diagnostic testing in symptomatic or high risk people.

- Health messages targeting the general population should be designed to emphasise that cardiovascular disease is an important cause of illness and death in women as well as men, and to educate people about symptoms that suggest the need for medical advice.

- Women in high risk groups should be screened more actively for cardiovascular disease at the primary care level.

- Clinical trials for cardiovascular disease should include more female patients.

- Further research is needed to explain why women have unequal access to treatments, or suffer more advanced disease when they seek medical care for cardiovascular disease, so that specific remedies may be designed.

\section{REFERENCES}

1 Regidor E, De Mateo S, Gutierrez-Fisac JL, et al. Diferencias socioeconómicas en la utilización y accesibilidad de los servicios sanitarios en España. [Socioeconomic differences in health services use and accessibility in Spain]. Med Clin (Barc) 1996;107:285-8.

2 Katz SJ, Hofer TP. Socioeconomic disparities in preventive care persist despite universal coverage. JAMA 1994;272:530-4

3 Adler EN, Boyce WT, Chesney AM, et al. Socioeconomic inequalities in health. JAMA 1993;269:3140-5.

4 García C, Solano A. Salud y desigualdad social. [Health and social inequality]. Med Clin (Barc) 1993;100:296-8.

5 Fernández E, Schiaffino A, Rajmil L, et al. Gender inequalities in health and health care services use in Catalonia (Spain). J Epidemiol Community Health 1999;53:218-22.

6 Berkanovic E, Telesky C. Mexican-American, Black American and White-American differences in reporting illness, disability and the seeking of health care for illness. Soc Sci Med 1985;20:567-74

7 Ministerio de Sanidad y Consumo. Encuesta Nacional de Salud 1997. [1997 National Health Survey]. Madrid: Ministerio de Sanidad y Consumo, 1995.

8 Ruiz MT, Verbrugge LM. A two way view of gender bias in medicine. J Epidemiol Community Health 1997;51:106-9.

9 Mosca L, Manson JE, Sutherland SE, et al. Cardiovascular disease in women: a statement for healthcare professionals from the American Heart Association. Circulation 1997;96:2468-82.

10 Beery TA. Gender bias in the diagnosis and treatment of coronary artery disease. Heart Lung 1995;24:427-35.

11 Hochleiter M. Coronary heart disease: sexual bias in referral for coronary angiogram. How does it work in a state-run health system? J Womens Health Gend Based Med 2000:9:29-34.

12 Wenger NK. Coronary heart disease in women: gender differences in diagnostic evaluation. J Am Med Womens Assoc 1994;49:181-5.

13 Silva Aiçaguer LC. Técnicas de Muestreo en Ciencias de la Salud. [Sampling techniques in the health sciences]. Madrid: Díaz de Santos, 1993.

14 Lázaro P, Fitch K, Martín Y. Estándares para el uso apropiado de la angioplastia coronaria transluminal percutánea y cirugía aorto-coronaria. [Criteria for the appropriate use of percutaneous transluminal coronary angioplasty and coronary artery bypass graft surgery]. Rev Esp Cardiol 1998;51:689-715.

15 Aguilar MD, Fitch K, Lazaro P, et al. The appropriateness of use of percutaneous transluminal coronary angioplasty in Spain. Int J Cardiol $2001 ; 78: 213-21$

16 Roger VL. Women less likely than men to undergo cardiovascular procedures for unstable angina. JAMA 2000;283:646-52.

17 Soler N, Bennet $M$, Pentecost B, et al. Myocardial infarction in diabetics. Q J Med 1975;173:125-32

18 Steingart RM, Packer $M$, HammP, et al. Sex differences in management of coronary artery disease. N Engl J Med 1991;325:226-30.

19 Healy B. The Yentl syndrome. N Engl J Med 1991;325:274-5.

20 Chiriboga DE, Yarzebski J, Goldbert RJ, et al. A community-wide perspective of gender differences and temporal trends in the use of diagnostic and revascularization procedures for acute myocardial infarction. Am J Cardiol 1993;71:268-73.

21 Schulman D, Berlin JA, Harless W, et al. The effect of race and sex on physicians recommendations for cardiac catheterization. N Engl J Med 1999;340:618-26

22 Council on Ethical and Judicial Affairs, AMA. Gender disparities in clinical decision making. JAMA 1991;266:559-62.

23 Cerqueira MD. Diagnostic testing strategies for coronary artery disease: special issues related to gender. Am J Cardiol 1995;75:52-60D. 
24 Steingart RM, Packer $M$, HammP, et al. Sex differences in management of coronary artery disease. N Engl J Med 1991;325:226-30.

25 Wilkinson P, Laji K, Ranjadayalan K, et al. Acute myocardial infarction in women: survival analysis in first six months. BM 1994;309:566-9.

26 Weaver WD, White HD, Wilcox RG, et al, for the GUSTO-I Investigators. Comparisons of characteristics and outcomes among women and men with acute myocardial infarction treated with thrombolytic therapy. JAMA 1996;275:777-82.

27 Ayanian JZ, Epstein AM. Differences in the use of procedures between women and men hospitalized for coronary heart disease. N Engl J Med 1991;325:221-5

28 Petticrew M, McKee M, Jones J. Coronary artery surgery: are women discriminated against? BM 1993;306:1164-6.

29 Clarke KW, Gray D, Keating NA, et al. Do women with acute myocardial infarction receive the same treatment as men? BM 1994:309:563-6.

30 Dong W, Ben-Shlomo Y, Colhoun H, et al. Gender differences in accessing cardiac surgery across England: a cross-sectional analysis of the health survey for England. Soc Sci Med 1998;47:1773-80.

31 Latour-Pérez J. Esfuerzo terapeútico al ingreso en mujeres con infarto agudo de miocardio. Grupo Valenciano para el estudio de las

desigualdades hospitalarias en salud. [Therapeutic effort at admission of women with acute myocardial infarction. Valencia Group for the study of hospital inequalities in health]. Comment in Med Clin (Barc) 1994;102:361-3.

32 Mark DB, Shaw LK, De Long ER, et al. Absence of sex bias in the referral of patients for cardiac catheterisation. N Engl J Med 1994;330:1101-6.

33 Roeters van Lennep JE, Zwinderman AH, Roeters van lennep HW, et al. Gender differences in diagnosis and treatment of coronary artery disease from 1981 to 1997 . No evidence for the Yentl syndrome. Eur Heart J 2000;21:911-18.

34 Cotton P. Examples abound of gaps in medical knowledge because of groups excluded from scientific study. JAMA 1990;263:1051-2.

35 Jenkins JS, Flaker GC, Nolte B, et al. Causes of higher in-hospital mortality in women than in men after acute myocardial infarction. Am J Cardiol 1994;73:319-22.

36 Bernstein SJ, Hilborne LL, Leape RE, et al. The appropriateness of use of cardiovascular procedures in women and men. Arch Intern Med 1994; 154:2759-65.

37 Herman J. Gender differences in coronary artery disease: bias, method or fact of life? Arch Fam Med 1993;2:365-6.

38 Bueno H, Vidán T, Almazán A, et al. Influence of sex on the short-term outcome of elderly patients with a first acute myocardial infarction. Circulation 1995;92:1133-40 